\title{
PENDAMPINGAN MILENIAL HOBI ZAKAT MELALUI PENGAPLIKASIAN ZAKAT DIGITAL BAGI REMAJA MASJID
}

\author{
Muhammad Subardin ${ }^{1)}$, Imelda Imelda1), Sri Andaiyani'1) \\ 1)Jurusan Ekonomi Pembangunan, Fakultas Ekonomi, Universitas Sriwijaya, Palembang, \\ Sumatra Selatan, Indonesia \\ Corresponding author: Sri Andaiyani \\ Email : sriandaiyani@fe.unsri.ac.id
}

Diterima 16 Juli 2021, Diterima 03 Agustus 2021, Disetujui 03 Agustus 2021

\begin{abstract}
ABSTRAK
Kegiatan pengabdian kepada masyarakat (PKM) ini memiliki tujuan untuk memberikan pemahaman mengenai zakat dan manfaat teknologi komunikasi guna mengaplikasikan zakat. Tim Pengabdian Fakultas Ekonomi UNSRI telah melaksanakan pendampingan kepada generasi milenial yang hobi zakat. Pelaksanaan kegiatan berlangsung 1 hari pada Jumat, 15 November 2019. Peserta terdiri dari 30 Remaja Mushola Ukhuwah Fakultas Ekonomi. Metode pelaksanaan kegiatan berupa memberikan ceramah dan tutorial. Tim PKM menyampaikan edukasi berkenaan dengan zakat, manfaat zakat dan jenis zakat. Peserta pendampingan diberikan tutorial penggunaan zakat digitial dan dapat menghitung zakat dengan aplikasi kitabisa.com. Untuk mengevaluasi kegiatan PKM, peserta pemdampingan diminta untuk mengisi kuisioner yang terkait dengan pemahaman materi. Berdasarkan hasil kuesioner, pendampingan zakat yang telah dilaksanakan menunjukkan pemahaman peserta yang telah mencapai $71 \%$. Capaian ini diharapkan dapat meningkatkan penggunaan zakat digital sebagai metode pembayaran zakat bagi generasi millennial.
\end{abstract}

Kata kunci : zakat; milenial; zakat digital.

\begin{abstract}
The community service activity (PKM) aims to provide an understanding of zakat and the benefits of communication technology to apply zakat. The team of Faculty of Economics UNSRI has provided assistance to the millennial generation who like zakat. The activity was carried out for 1 day on Friday, November 15, 2019. The participants consisted of 30 Youths of the Ukhuwah Mosque, Faculty of Economics. The method of carrying out activities is in the form of giving lectures and tutorials. The PKM team delivered education regarding zakat, the benefits of zakat and the types of zakat. Mentoring participants are given tutorials on the use of digital zakat and can calculate zakat with the kitabisa.com application. To evaluate PKM activities, mentoring participants were asked to fill out a questionnaire related to understanding the material. Based on the results of the questionnaire, the zakat assistance that has been implemented shows the participants' understanding which has reached $71 \%$. This achievement is expected to increase the use of digital zakat as a method of paying zakat for the millennial generation.
\end{abstract}

Keywords : zakat; millennial; digital zakat.

\section{PENDAHULUAN}

Pada masa serba digital saat ini, penggunaan gadget yang canggih telah menjadi sesuatu yang lumrah bagi generasi milenial di Indonesia, tak terkecuali kalangan milenial yang mapan dan kalangan ekonomi menengah dengan pemikiran yang terbuka dan responsive terhadap perubahan. Di samping itu, Public figure akan mempengaruhi penerimaan informasi oleh masyarakat dan menjadikan konten konten yang mereka posting di media sosial sebagai inspirasi untuk melakukan sesuatu. Perkembangan teknologi ini membawa perubahan yang tidak dapat dihindari. Ditinjau dari pilantrofi islam, teknologi memengaruhi pertumbuhan dan perkembangan muzaki. Demografi muzaki semakin kini semakin banyak dan beragam, utamanya dari kalangan

Saat ini, pengetahuan muslim di Indonesia mengenai fiqih dan akidah keislaman relative meningkat. Generasi muda Indonesia semakin sadar akan pentingnya ilmu agama. Beberapa generasi muda mulai beralih hijrah dari pekerjaan yang mengandung riba, gaya berpakian yang tidak sesuai dengan syariat, makanan halal, dan gaya hidup lainnya. berbagai sisi mulai dari pekerjaan, gaya berpakaian, makanan, pendidikan, serta generasi muda saai ini mulai antusias untuk 
mendiskusikan dan mendalami ilmu agama terutama generasi milenial. Generai ini merupakan generasi yang lahir pada tahun 1980-2000 atau berusia 19-39 tahun. Ainiyah (2018) menyatakan bahwa kaum milenial telah pandai menggunakan teknologi informasi yang canggih dan medial sosial seperti facebook, email, twitter dan lain-lain. Hal ini tentunya menjadikan generasi milenial hidup dan berkembang di era digital.

Generasi ini mulai tertarik dengan tata kelola keuangan dan dunia lembaga keuangan. literasi keuangan bagi generasi milenial ini sudah berkembang dengan baik. Hal ini juga tak lepas dari edukasi yang diberikan oleh berbagai pihak seperti Otoritas Jasa Keuangan, Perbankan, Fintech, dan lain-lain. Perkembangan teknologi yang membuat kondisi saat ini yang serba digital termasuk dalam membayar zakat.

Secara normatif, Zakat adalah kewajiban yang diberikan kepada setiap muslim sebagai bentuk pelaksanaan rukun islam. Menunaikan zakat merupakan ibadah yang mempresentasikan rasa kepedulian antara sesama muslim dan menjadi dukungan moril dan material sekaligus mengangkat derajat dan martabat sesama muslim.

Zakat memberikan implikasi positif terhadap kesejahteraan masyarakat. Dalam pelaksanaannya yang sesuai ketentuan yang berlaku, zakat membantu distribusi harta dari pemilik harta ( Muzaki ) kepada penerima zakat (Mustahik) yang mendukung kesejahteraan sehingga masyarakat yang fakir dan miskin dapat memenuhi kebutuhan konsumsi dan dapat melakukan aktifitas ekonomi dengan baik dan melakukan kegiatan produktif lainnya. Dengan demikian, para mustahik juga dapat berubah statusnya menjadi mustahiq (Baznas, 2019);(Mubarokah, Beik, \& Irawan, 2018); (Agustin, 2020); (Kholid, 2020).

Pelatihan ini akan membimbing remaja masjid untuk menggunakan gadget pada hal hal yang bermanfaat dan produktif daripada hanya sekedar nge-game. Oleh karena itu, dengan adanya pengabdian ini, menginisiasi untuk mengarahkan para remaja masjid menggunakan gadget yang dimilikinya untuk melakukan inovasi pembayaran zakat secara digital dengan cara yang lebih efisien. "Kebanyakan para remaja sudah memiliki gadget yang canggih yang setiap saat terhubung dengan internet. Selama ini mereka hanya update status dan lebih banyak bermain game online,". Guna mengarahkan remaja masjid atau kaum milenial ke hal-hal yang lebih bermanfaat, intervensi kepada remaja agar gadget dimanfaatkan untuk hal-hal yang lebih baik lagi.
Program pengabdian kepada masyarakat dengan aktivitas belajar mengajar di kampus merupakan bentuk penerapan gaya masa kini (kaum milenial) agar dapat lebih produktif lagi dengan kemajuan zaman dengan berbagai inovasi untuk penerapan zakat. Lalu, berdasarkan pemaparan pendahuluan di atas, kami memilih beberapa permasalahan yang dijadikan focus utama untuk ditelusuri melalui kegiatan pengabdian ini, secara terperinci adalah tentang bagaimana memberikan pemahaman mengenai pentingnya proses zakat dengan cara yang lbih efisien dan pemahaman tentang perhitungan zakat dan keuangan bagi remaja masjid? Bagaimana potensi muzaki milenial tentang inovasi teknologi untuk zakat? dan terakhir bagaimana peran milenial sebagai penggerak di setiap kegiatan ekonomi?.

Kegiatan pengabdian masyarakat ini diharapkan akan bermanfaat bagi remaja masjid di sekitaran daerah Indralaya, Ogan Ilir. Semoga kegiatan ini bermanfaat dengan penerapan ilmu yang diberikan. Sehingga para milenial muslim mampu menjadi penyampai informasi yang baik. Selain itu mereka juga dapat berperan sebagai relawan hingga menjadi amil zakat dengan ditunjang pelatihanpelatihan yang membantu meningkatkan pengetahuan dan keterampilan.

\section{METODE}

Sasaran yang dipilih pada pelaksanaan pengabdian kepada masyarakat adalah para kaum millennial atau remaja masjid di daerah Indralaya, Ol sebanyak 30 peserta. Penetapan sasaran ini merupakan suatu upaya untuk melakukan peningkatan potensi kaum milenial/ remaja masjid. Peserta diharapkan dapat menularkan ilmu yang didapatkan kepada para remaja lain yang berada di sekitarnya. Kegiatan pengabdian masyarakat ini dilakukan di mushola Ukhuwah Fakultas Ekonomi, Kabupaten Ogan ilir dengan sasaran pelaku kaum milenial atau remaja masjid.

Ada beberapa metode pelaksanaan yang akan dilakukan yakni:

\section{Ceramah}

Tim Pengabdian memberikan edukasi serta literasi terkait dengan zakat dan digital zakat yang disampaikan oleh Bapak Muhammad Subardin selaku Ketua Tim PKM.

\section{Tutorial}

Dalam hal ini peserta pelatihan diberikan pendampingan dalam mengunduh dan mengaplikasikan zakat digital platform yaitu Apikasi KITABISA.

\section{Diskusi dan Evaluasi}

Setelah sesi tutorial, peserta diberi kesempatan untuk diskusi dan Tanya jawab. Di akhir sesi, 
tim pengabdian akan mengevaluasi kegiatan melalui kuisioner peserta.

Prosedur pembayaran zakat melalui aplikasi KITABISA:

1. Memasang aplikasi tersebut terlebih dahulu kemudian masuk dengan menggunakan akun Google/Facebook.

2. Selanjutnya ketuk fitur Zakat $\rightarrow$ pilih lembaga mitra amil zakat miliki KITABISA $\rightarrow$ ketuk fitur Zakat Langsung.

3. Kemudian langkah selanjutnya adalah memilih BAZNAZ $\rightarrow$ Tunaikan Zakat dibagian paling bawah $\rightarrow$ isi nominal zakat yang akan di bayarkan serta pilih metode pembayaran $\rightarrow$ ketuk Zakat $\rightarrow$ Kamu akan mendapatkan total zakat yang harus di bayarkan beserta nomer rekening.

Indikator capaian dalam kegiatan ini adalah ada peningkatan pemahaman tentang zakat dan pengaplikasiannya melalui aplikasi dari awalnya hanya sekedar membaca informasi yang ada dan hanya sebatas tahu hingga menjadi tertarik untuk menerapkan dan memahaminya untuk bisa dibagikan kepada yang lainnya. Pemahaman ini diukur dengan cara memberikan beberapa pertanyaan terkait materi pendampingan yang telah diberikan serta praktek langsung penggunaan aplikasi zakat digital ini. Sehingga bisa dilihat seberapa besar presentase keberhasilan dari kegiatan ini dan seberapa dalam pemahaman para peserta. Besaran standar capaian evaluasi dalam kegiatan ini yang diterapkan adalah sebesar $70 \%$, dikarenakan seharusnya pelatihan mengenai implementasi zakat melalui aplikasi ini tidak dilakukan hanya sekali harusnya dilakukan secara berkala sampai zakat online ini menjadi suatu kebiasaan yang tidak lagi asing bagi para kaum milenial muslim. Besaran standar capaian evaluasi sebesar $70 \%$ ini diambil sesuai teori Return On Training Investment (ROTI) dimana proses pelatihan dibagi menjadi 3 fase yaitu input/context (pemberian pelatihan dan pengarahan) , process(pendalaman) , dan product (kemampuan dan perubahan baru setiap peserta pelatihan). Pada tahap pertama jika nilai evaluasi didapat pada range $70-80 \%$ maka sudah dikategorikan baik, yaitu sarana dan prasarana serta penyampaian materi baik juga respon dari para peserta dalam memahami isi pelatihan.

\section{HASIL DAN PEMBAHASAN}

Pelaksanaan pendampingan milenial hobi zakat melulai aplikasi zakat digital remaja masjid di Mushola Ukhuwah Fakultas Ekonomi, Indralaya. Pelatihan ini diikuti oleh 30 remaja mushola yang merupakan mahasiswa fakultas ekonomi. Pelaksanaan kegiatan dilakukan pada hari Jum'at 15 November 2019. Kegiatan diawali dengan memberikan modul yang berkaitan tentang materi pengelolaan zakat oleh ketua pelaksana. Selanjutnya, ketua tim pengabdian menjelaskan materi yang tertera di dalam modul dengan bantuan tayangan power point agar materi lebih jelas tersampaikan intinnya dan mudah dipahami dengan dibantu anggota pelaksana.

Beberapa materi yang disampaikan terkait zakat, yaitu menurut BAZNAS (Badan Amil Zakat Nasional) Zakat merupakan salah satu rukun islam dan menjadi unsur pokok bagi penegakan syariat islam juga dalam Kitab AlHawi, Al-Mawardi mendefinisikan pengertian zakat dengan nama pengambilan tertentu, dari harta yang tertentu, menurut sifat-sifat tertentu, dan untuk diberikan kepada golongan tertentu. Zakat sendiri pada dasarnya dibagi menjadi dua yaitu, Zakat Nafs (Jiwa) disebut juga Zakat Fitrah dan Zakat Maal (Harta) yang memiliki manfaat sebagai pelindung dan pembersih harta dunia dan sebagai salah satu cara yang dirahmati Allah untuk berbagi. Maka dari itu, zakat sangat penting untuk ditunaikan sebagai salah satu cerminan diri umat muslim yang bertakwa dan bentuk rasa syukur dan berterimakasih kepada Allah atas segala nikmat yang didapatkan.

Kemudian, peserta diarahkan untuk mengunduh aplikasi zakat berbasis android serta cara menggunakan aplikasi tersebut. Nantinya Peserta akan mendapatkan ilmu dan pengetahuan khusus tentang zakat online. Pelaksana program juga akan mengajak semua peserta untuk mendemontrasikan pengetahuan tersebut dalam bentuk penggunaan aplikasi zakat dengan memasukkan pengeluaran dan pendapatannya. Tak lupa, para pelaksana memberikan tutorial satu persatu proses yang dilalui daam mengakses aplikasi dan menunaikan zakat online agar mengurangi tingkat kesalahan. Hingga diakhir, diberikan pertanyaan sebagai bentuk evaluasi kegiatan sampai sejauh mana pemahaman peserta terhadap materi yang disampaikan dan bagaimana para peserta menggunakan aplikasi kitabisa.com untuk menunaikan zakat online dengan mudah.

Era industri 4.0 telah mengubah cara kerja dan layanan akses keuangan. Teknologi sudah semakin maju sehingga pelayananan menjadi efisien dan efektif. Penggunaan berbagai aplikasi dan fitur keuangan pada Gawai atau gadget adalah suatu tren dalam pemenuhan kebutuhannya. 


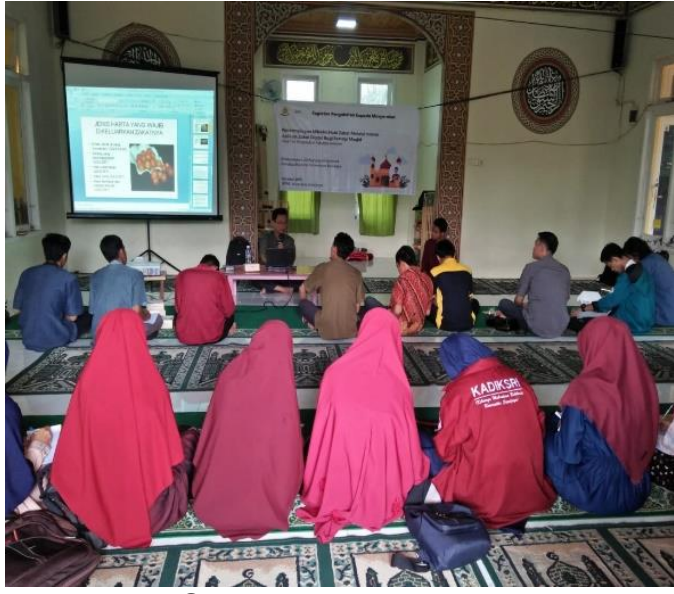

Gambar 1. Suasana Pelatihan dan Edukasi.

Edukasi mengenai Zakat kepada generasi millenial sangat dibutuhkan untuk menambah pengetahuan akan manfaat aplikasi zakat yang berbasis teknologi untuk menjadi alternative penggunaan. Jumlah peserta pengabdian kepada masyarakat di mushola ukhuwah sebanyak 30 orang. Selain itu, 30 pelaku peserta telah menggunakan gawai atau gadget. Hal ini dapat mendukung kegiatan pengabdian masyarakat ini karena peserta telah sesuai dengan target. Hal ini didukung oleh Purwakananta (2020) yang menyatakan bahwa penggunaan platform media digital sebagai alternative pembayaran zakat telah digunakan mulai dari tahun 2016.

Tim pelaksana pengabdian memberikan materi terkait zakat. Kemudian peserta diminta untuk mengunduh aplikasi kitabisa.com. peserta dibimbing dan diarahkan dalam menggunakan aplikasi tersebut. Selama diberikan edukasi dan pelatihan peserta sangat antusias dan berusaha untuk mencerna dengan baik terkait ilmu yang disampaikan dan selanjutnya mulai mencoba untuk melihat berbagai aplikasi zakat online lainnya. Ada beberapa langkah dalam menggunakan aplikasi kitabisa.com.

Langkah pertama adalah download aplikasi melalui playstore (Lihat Gambar 2). Jika sudah memiliki akun maka hanya tinggal login (masuk), bagi pengguna baru maka harus melakukan pendaftaran.

\section{$\leftarrow \quad$ kitabisa \\ Q ?}

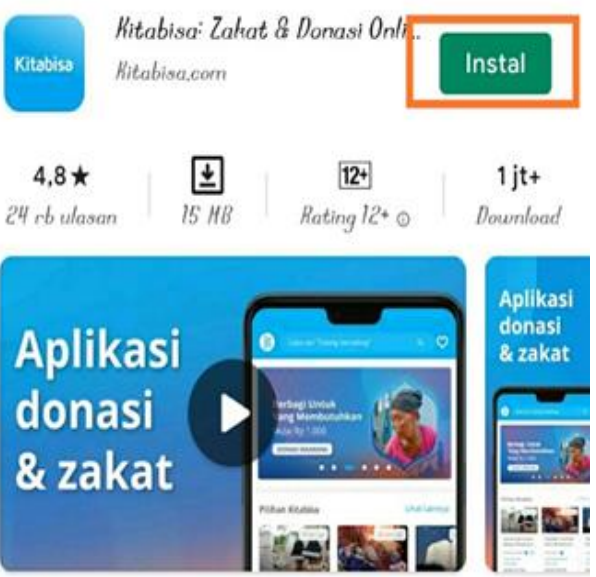

Horrudathkan anda Zahat, dan Donasi Onlino Pahai Gopay. DANA. Shopeepay dan Jenius

Gambar 2. Download Aplikasi Kitabisa.com.

Dalam mendaftar akun kitabisa.com, peserta dapat masuk melalui akun google, akun facebook atau akun apple. Hal ini tentunya dapat mempermudah peserta dalam masuk ke akun kitabisa.com. Gambar 3 menunjukkan tampilan apabila peserta ingin mendaftar melalui akun google maka akan tampil verifikasi akun email peserta, seperti pada gambar 4 .

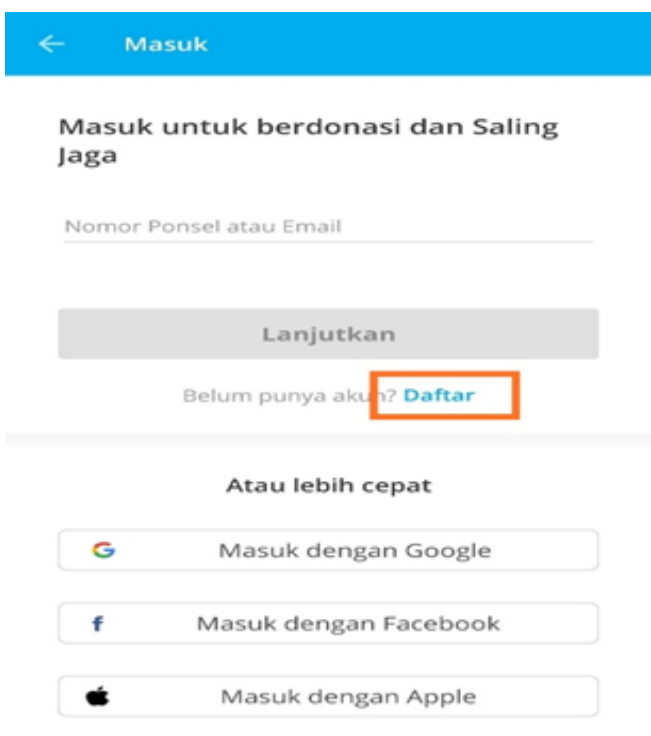

Gambar 3. Pendaftaran Akun Kitabisa.com. 


\section{$\leftarrow \quad$ Daftar}

Perjalanan kebaikanmu dimulai di sini

Masukkan 6 digit kode yang kami kirim ke Masukkan6 digit kode yan
ggmail.com

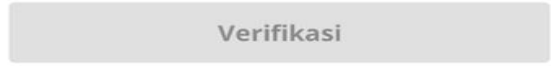

Belum menerima kode verifikasi

Kirim ulang kode dalam 00:25

Gambar 4. Verifikasi Akun dengan Email.

Langkah kedua peserta diminta untuk memasukan nomer handphone yang aktif dan nama lengkap kemudian klik daftar seperti pada Gambar 5. Setelah data telah terisi dengan lengkap maka pendaftar diminta untuk membuat kata sandi guna keamanan akun pendaftar.

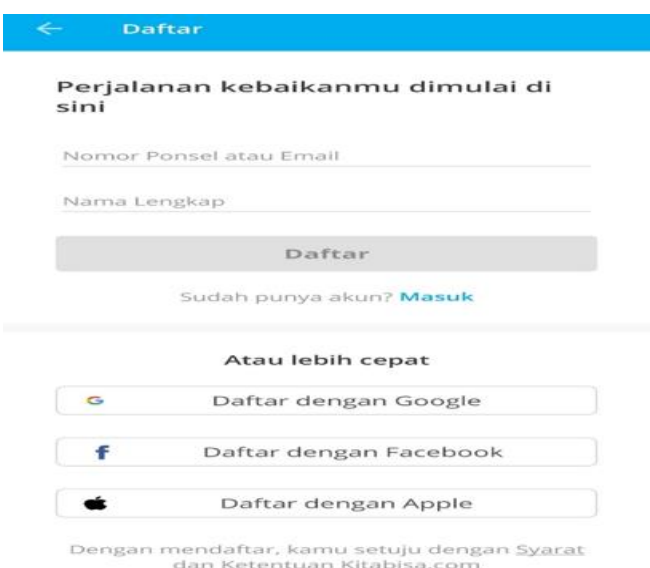

Gambar 5. Melengkapi Data.

Langkah ketiga, pendaftaran peserta berhasil maka akan muncul tampilan beranda Untuk memulai menggunakan aplikasi kitabisa.com dalam membayar zakat atau berdonasi maka pemilik akun bisa mengisi saldo terlebih dahulu untuk memudahkan transaksi atau memilih berbagai produk yang tersedia seperti 'zakat', agar bisa memilih jenis zakat dan menghitung besarnya terlebih dahulu. Kali ini, kita akan klik isi saldo terlebih dahulu. Akan muncul tampilan pada Gambar 6 sebagai berikut:

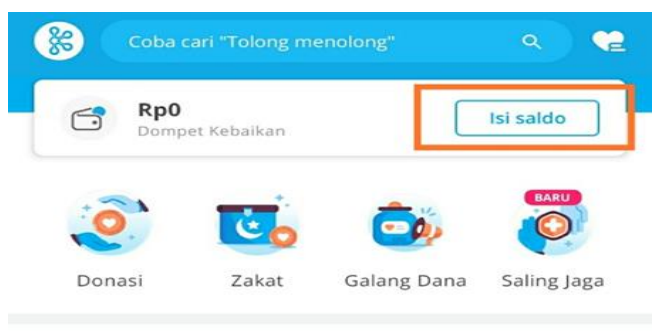

Penggalangan Dana Mendesak
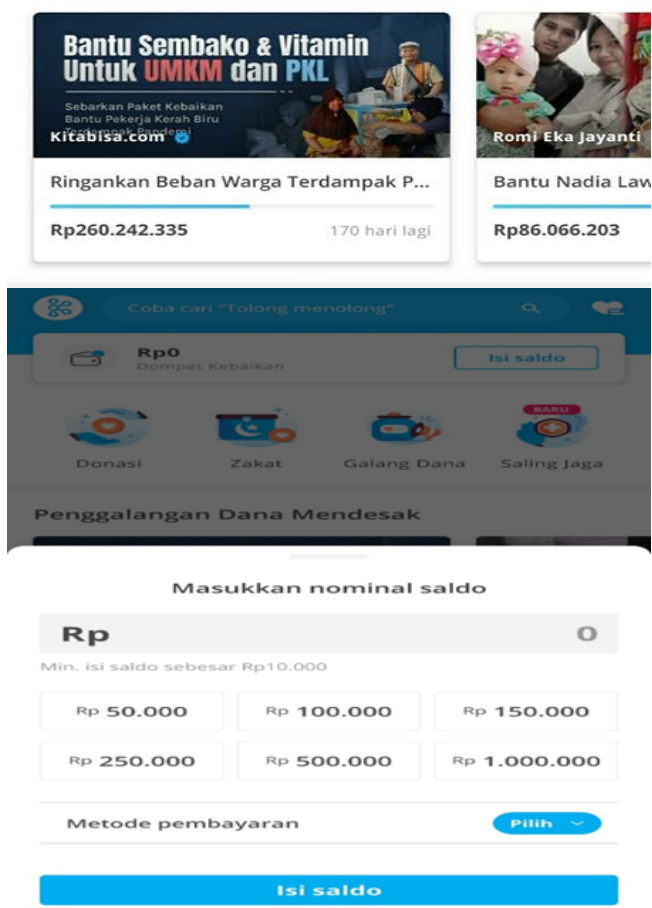

Gambar 6. Pengisian Saldo

Setelah selesai pengisian saldo, maka pemilik akun sudah bisa melakukan transaksi zakat. Selanjutnya, pemilik akun sudah bisa membayar zakat dengan mengklik "salurkan" seperti pada gambar 8 atau menghitung terlebih dahulu jumlah zakat yang akan disalurkan dengan mengklik "kallkulator" seperti pada tampilan gambar 7 .

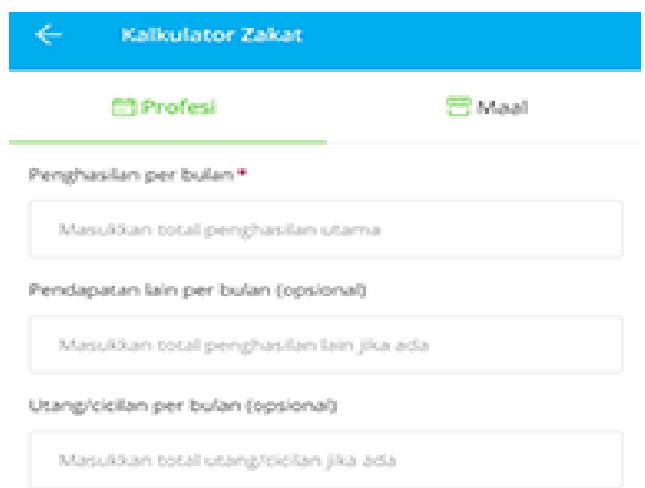

Hitung Zaka:

Gambar 7. Tampilan Kalkulator Zakat 


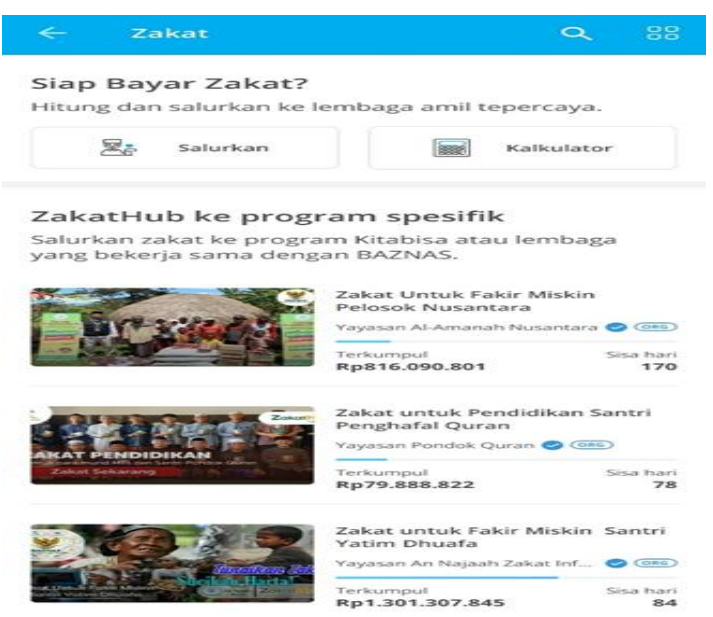

Gambar 8. Tampilan Bayar Zakat

Hasil dari edukasi terkait zakat online, tercapai pemahaman sebesar $71 \%$ yaitu persentase angka yang melebihi standar capaian yaitu sebesar $70 \%$. Berdasarkan temuan dari Irhamsyah (2019) dan Tantriana \& Rahmawati (2019), informasi teknologi dan zakat digital belum terbukti berpengaruh pada keputusan membayar zakat secara digital. Oleh karena itu, kegiatan PKM ini diharapkan dapat meningkatkan minat remaja mesjid dalam menggunakan aplikasi zakat digital.

Tabel 1. Presentase Pemahaman Materi Edukasi dan Pelatihan.

\begin{tabular}{|c|c|c|c|c|}
\hline $\begin{array}{l}N \\
0\end{array}$ & $\begin{array}{l}\text { Butir } \\
\text { Pertanyaan }\end{array}$ & $\begin{array}{l}\text { Kod } \\
\text { e }\end{array}$ & $\begin{array}{l}\text { Penilaia } \\
\mathrm{n}\end{array}$ & $\begin{array}{l}\text { Persentas } \\
\text { e }\end{array}$ \\
\hline 1 & $\begin{array}{l}\text { Pemahaman } \\
\text { mengenai } \\
\text { zakat }\end{array}$ & Q1 & 3.4 & $68 \%$ \\
\hline 2 & $\begin{array}{l}\text { Pemahaman } \\
\text { mengenai } \\
\text { macam zakat }\end{array}$ & Q2 & 3.7 & $74 \%$ \\
\hline 3 & $\begin{array}{l}\text { Pemahaman } \\
\text { mengenai } \\
\text { perhitungan } \\
\text { zakat }\end{array}$ & Q3 & 3.4 & $68 \%$ \\
\hline 4 & $\begin{array}{l}\text { Pemahaman } \\
\text { mengenai } \\
\text { pentingnya } \\
\text { zakat }\end{array}$ & Q4 & 3.7 & $74 \%$ \\
\hline 5 & $\begin{array}{l}\text { Pemahaman } \\
\text { dalam } \\
\text { mengunduh } \\
\text { aplikasi zakat }\end{array}$ & Q5 & 3.8 & $76 \%$ \\
\hline 6 & $\begin{array}{l}\text { Pemahaman } \\
\text { cara } \\
\text { mengaplikasik } \\
\text { an zakat digital } \\
\text { di Smartphone }\end{array}$ & Q6 & 3.4 & $68 \%$ \\
\hline \multicolumn{2}{|c|}{ Rata-rata } & & 3.56 & $71 \%$ \\
\hline
\end{tabular}

Metode penyampaian materi dan pelatihan terhadap penggunaan aplikasi kitabisa.com untuk menunaikan zakat kali ini terbilag lebih efisien karena dapat langsung menyampaikannya kepada orang yang tepat dan merasakan serta melihat langsung bagian mana yang belum dipahami atau keliru dipahami, sehingga para peserta dapat mendapatkan peningkatkan daya pahamnya.

Penggunaan aplikasi kitabisa.com dapat memberikan kemudahan bagi kaum milenial dalam membayar zakat. Hal ini didukung oleh penelitian Windi Astuti \& Budi Prijanto (2020) yang menunjukkan bahwa minat muzaki dalam membayar zakat melalui Kitabisa.com dipengaruhi oleh persepsi kemudahan penggunaan, sikap, norma subjektif, persepsi kontrol perilaku. Penelitian ini membuktikan bahwa persepsi kemudahan penggunaan berpengaruh signifikan terhadap persepsi kegunaan. Kemudian, persepsi kegunaan dan persepsi kemudahan penggunaan berpengaruh signifikan terhadap sikap. Di samping itu, persepsi kemudahan penggunaan, sikap, norma subjektif, dan persepsi kontrol perilaku berpengaruh signifikan terhadap minat menggunakan layanan zakat digital Kitabisa.com. Dapat ditarik kesimpulan bahwa alasan utama seseorang tertarik menggunakan Fintech dalam menunaikan zakat terutama kitabisa.com adalah karena kemudahannya. Fintech memberikan kemudahan dalam melakukan transaksi zakat dan dapat menarik massa masyarakat muslim lebih banyak untuk melaksanakan kewajiban berzakatnya (Afiful Ichwan \& Ruslan Abdul Ghofur, 2020).

Semakin beragamnya teknologi yang ada dan fungsinya, tentunya minat milenial untuk mempelajari dan menggunakannya akan semakin tinggi. Tidak heran, beberapa kegiatan agama juga perlu disesuaikan dengan penggunaan teknologi termasuk zakat. Sehingga, muzakki dari kaum milenial lebih banyak terserap. Karena peran milenial terhadap setiap kegiatan yang bisa menggerakkan perekonomian terbilang cukup tinggi. Karena jiwa milenial yang selalu ingin mencoba hal baru dan memiliki rasa penasaran yang tinggi. Tentunya, diimbangi daya cekatan dan kemampuan berinovasi yang luar biasa, lebih aktif daripada generasi terdahulu sehingga tidak jarang lebih bisa diandalkan. Ketika generasi tua hanya bisa melangkah sejauh tiga langkah maka para kaum milenial bisa melangkah sampai garis finish karena faktor fisiknya saja.

\section{SIMPULAN DAN SARAN}

Kegiatan PKM telah terlaksana dengan baik melalui pendampingan kepada generasi millennial yang hobi zakat. Pelaksanaan PKM telah berlangsung pada Jum'at, 15 November 
2019. Peserta PKM terdiri dari 30 remaja mesjid ukhuwah fakultas ekonomi. Tim pelaksana memberikan modul mengenai zakat, manfaat dan jenis zakat. Peserta dapat menghitung zakat dengan aplikasi kitabisa.com. Sebagai evaluasi PKM, tim membagikan kuisioner pada seluruh peserta PKM. Berdasarkan hasil kuesioner, pemahaman peserta PKM setelah mendapat pedampingan zakat digital telah mencapai $71 \%$. Kegiatan PKM ini diharapkan dapat meningkatkan minat generasi milenial dalam menggunakan aplikasi zakat digital.

Namun, saran yang bisa diberikan untuk kegiatan pendampingan selanjutnya berdasarkan kekurangan saat ini di mana tidak ada pendampingan secara berkala setelah kegiatan sehingga tidak diketahui pasti efek selanjutnya makaakan lebih baik pendampingan secara berkala dapat diterapkan di kegiatan selanjutnya. Agar materi yang diberikan bisa lebih efektif dipraktekkan dan benar-benar bisa memberikan dampak positif yang signifikan.

\section{UCAPAN TERIMAKASIH}

Terima kasih kami ucapkan pada Rektor Universitas Sriwijaya telah memberikan hibah pengabdian melalui Lembaga Penelitian dan Pengabdian Masyarakat Universitas Sriwijaya.

Keberhasilan pelaksanaan PKM dan penyusunan artikel ini tidak terlepas dari bantuan berbagai pihak. Ucapan terima kasih kami sampaikan pada Ketua Umum BO Ukhuwah Fakultas Ekonomi, UNSRI.

\section{DAFTAR RUJUKAN}

Agustin, L. (2020). Dampak Zakat Terhadap Kesejahteraan Mustahiq Berdasarkan Indeks Kesejahteraan Baznas. Ejournal.lainsurakarta.Ac.ld.

Ainiyah, N. (2018). Remaja Millenial dan Media Sosial: Media Sosial Sebagai Media Informasi Pendidikan Bagi Remaja Millenial. Jurnal Pendidikan Islam Indonesia. https://doi.org/10.35316/jpii.v2i2.76

Astuti, W., \& Prijanto, B. (2020). Faktor yang Memengaruhi Minat Muzaki dalam Membayar Zakat Melalui Kitabisa.com: Pendekatan Technology Acceptance
Model dan Theory of Planned Behavior. https://doi.org/10.29244/jam.9.1.21-44.

Baznas. (2019). Dampak Zakat Terhadap Kesejahteraan Mustahik Evaluasi Program Zakat Produktif 2018. Baznas.

Ichwan, A., \& Ghofur, R., A. (2020). Pengaruh Technology Acceptance Model Terhadap Keputusan Muzakki Membayar Zakat Melalui Fintech Gopay http://dx.doi.org/10.29040/jiei.v6i2.1011.

Irhamsyah, A. (2019). Analisis Faktor-Faktor Preferensi Yang Mempengaruhi Keputusan Metode Pembayaran Zakat Bagi Muzakki Di Era Digital. Jurnal Ilmiah.

Kholid, A. N. (2020). Dampak Zakat, Infak Dan Sedekah (Zis) Terhadap Penurunan Tingkat Kemiskinan Dan Percepatan Pengentasan Kemiskinan. Jurnal Bina Ummat: Membina Dan Membentengi Ummat.

https://doi.org/10.38214/jurnalbinaummat stidnatsir.v2i01.40

Mubarokah, I., Beik, I. S., \& Irawan, T. (2018). Dampak Zakat terhadap Kemiskinan dan Kesejahteraan Mustahik (Kasus: BAZNAS Provinsi Jawa Tengah). AlMuzara'ah. https://doi.org/10.29244/jam.5.1.37-50

Purwakananta, arifin M. (2020). BAZNAS Ajak Masyarakat Zakat Digital. Badan Amil Zakat Nasional.

Rohmah, I., R., Ibdalsyah, \& Kosim, A., M. (2020). Pengaruh Persepsi Kemudahan Berdonasi, Dan Efektifitas Penyaluran Menggunakan Fintech Crowdfunding Terhadap Minat Membayar Zakat, Infaq, Shodaqoh. http://dx.doi.org/10.32832/kasaba.v13i1.3 397.

Tantriana, D., \& Rahmawati, L. (2019). The Analysis of Surabaya Muzaki's Preference for Zakat Payment through Zakat Digital Method. International Conference of Zakat. https://doi.org/10.37706/iconz.2018.118 